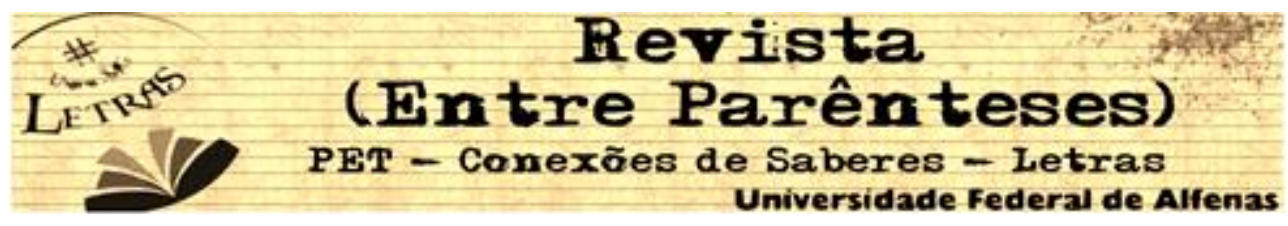

\title{
A FÓRMULA DA RESISTÊNCIA: uma interpretação da leitura deleuziana de Bartleby
}

\author{
Samuel Rezende ${ }^{1}$ \\ Universidade Federal de Minas Gerais \\ (rezende_s@hotmail.com)
}

Resumo: Bartleby, o escrivão de Herman Melville, é um personagem que resiste à referência. Sendo assim, apresenta-se aqui um percurso que deve apontar para um sumário entendimento do que seja, em Bartleby, resistência. Tal percurso entrecruza dois movimentos: o primeiro visa à compreensão da fórmula, "preferiria não", como um entrave no seio do sistema linguístico, desdobrando-a, posteriormente, em certo efeito agramatical. Já o segundo movimento passa pela ideia que apreende o escrivão como um "sujeito sem referência", um personagem "original". No entanto, ambos os movimentos devem ser assumidos como justificativas à leitura de Deleuze contra uma interpretação tradicional de Bartleby.

Palavras-chave: Resistência; Bartleby; Deleuze.

Abstract: Bartleby, the Herman Melville' scrivener, is a kind of character that resists to any reference. In this way, I present here a course which must appoint to a brief understanding of what can be, in Bartleby, resistance. That course interlaces two movements: the first one seek for a comprehension of the formula, "I would prefer not to", as a barrier in the middle of the linguistic system, being unfolded, later, in a kind of agrammatical effect. Thus the second movement passes by the idea that assumes the scrivener as a "man without reference", as an "original" character. However, both movements must be understood under the Deleuze reading against the traditional interpretation of Bartleby.

Keywords: Resistance; Bartleby; Deleuze.

Resumen: Bartleby, el escribiente de Herman Melville, es un personaje que resiste a la referencia. De esta forma, se presenta aquí un camino que debe apuntar para un breve entendimiento de lo que sea, en Bartleby, la resistencia. Ese camino entrecruza dos movimientos: el primero busca la comprensión de la fórmula, "preferiría no", como un entrabe en el seno del sistema lingüístico, desdoblándola, posteriormente, en un efecto agramatical. El segundo movimiento pasa por la idea que concibe el escribiente como un "sujeto sin referencia", como un personaje "original". Sin embargo, ambos movimientos deben ser comprendidos como justificativos en la lectura de Deleuze contra la interpretación tradicional de Bartleby.

Palabras Clave: Resistencia; Bartleby; Deleuze.

A fórmula proferida por Bartleby, personagem criada por Herman Melville, na

\footnotetext{
${ }^{1}$ Mestrando em Estudos Literários e bolsista CAPES.
} 


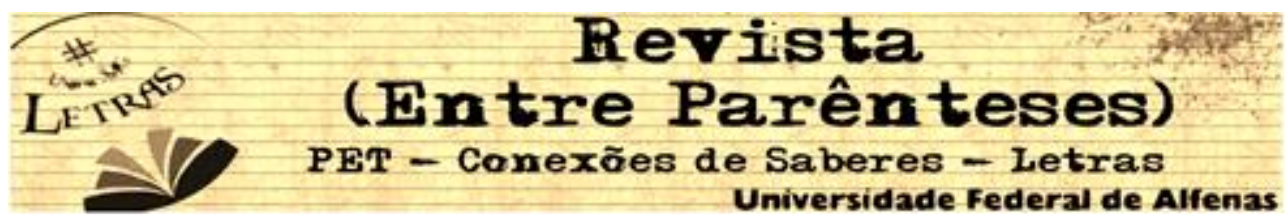

célebre expressão "eu preferiria não", torna-se aqui a primeira justificativa à leitura que o filósofo francês Gilles Deleuze empreende sobre o texto do escritor norteamericano. O modo como o filósofo compreende a fórmula lançada pelo escrivão, Bartleby, mostra-se, na verdade, como uma oposição à compreensão tradicional da personagem como "metáfora do escritor" ou ainda como um símbolo. A maneira como Bartleby articula a linguagem é uma primeira face do estranhamento causado pela fórmula, pois o emprego do verbo, "preferiria", parece não condizer com o seu uso frequente e, por isso, durante as ações no conto, leva estranheza, por exemplo, aos ouvidos do advogado dono do escritório para o qual trabalha o escrivão.

Imagine-se minha surpresa, ou antes, a minha consternação, quando, e sem se mover do seu retiro, Bartleby - numa voz singularmente suave e firme, me respondeu: - Preferiria não ("I would prefer not to").

Permaneci sentado um momento, em silêncio, tentando recompor as minhas faculdades aturdidas (MELVILLE, 2007, p. 84).

Tal estranhamento, causado pela frase, não se relaciona a erros gramaticais ou sintáticos, pois, estruturalmente, trata-se de uma forma correta, mesmo que o seu uso não seja corriqueiro. Na verdade, o que está em jogo é a pura falta de referência que faz com que se desarticule a compreensão.

Toda linguagem tem referências ou pressupostos (...). Uma palavra supõe sempre outras palavras que podem substituí-la, completá-la ou formar com ela alternativas: sob essa condição a linguagem se distribui de modo a designar coisas, estados de coisas e ações, segundo um conjunto de convenções objetivas, explícitas (DELEUZE, 2011, p. 96-97).

O incômodo ou estranhamento diz respeito ao fato de a frase não determinar o que Bartleby recusa, ou seja, não indica um posicionamento do escrivão e, por isso, adquire um caráter radical. O que dá ensejo à compreensão que confere radicalidade à fórmula é a própria indeterminação em não ser nem afirmação, nem 


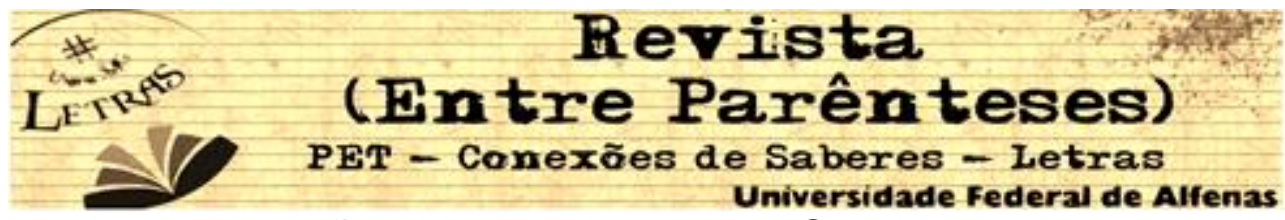

negação, pois Bartleby não recusa e nem aceita. Sendo assim, torna-se impossível aos seus pares de trabalho determinar o que de fato ele deseja. É dessa maneira que o escrivão parece estar envolto naquilo que Deleuze nomeia de "zona de indiscernibilidade", pois dizer "preferiria não" elimina impiedosamente tanto o preferível como o não preferível.

[A fórmula] cava uma zona de indiscernibilidade, de indeterminação, que não para de crescer entre algumas atividades não preferidas e uma atividade preferível. Qualquer particularidade, qualquer referência é abolida. A fórmula aniquila "copiar", a única referência em relação à qual algo poderia ser ou não ser preferido (idem, p. 94).

Esse lugar indiscernível em que Deleuze situa a sentença de Bartleby desmorona o duplo sistema referencial da linguagem, seja aquele que designa coisas e ações fora da linguagem ou aquele autorreferencial. É, portanto, nesse sentido que Giorgio Agamben, na esteira de Deleuze, acrescenta que a fórmula, por possuir um caráter anafórico absoluto, faz com que a frase perca toda a referência, não se remetendo mais nem a um objeto real, nem a outro termo na própria frase.

É como se o to que conclui a fórmula, que tem caráter anafórico (...) se absolutizasse até perder toda referência, voltando-se, por assim dizer, sobre a própria frase: anáfora absoluta, que gira sobre si mesma, sem se remeter mais nem a um objeto real nem a um termo anaforizado (I would prefer not to prefer not to...) (AGAMBEN, 2015, p. 29).

Seja como indiscernível, para Deleuze, ou anáfora absoluta, para Agamben, o dizer do escrivão resiste porque não guarda nenhuma referência interna ou externa, na verdade, ele "exclui qualquer alternativa e engole o que pretende conservar assim como descarta qualquer outra coisa" (DELEUZE, 2011, p. 97). A fórmula de Bartleby, portanto, encontra-se num lugar indeterminado, em que não há nenhuma indistinção entre as palavras, criando-se, assim, um "vazio na linguagem".

Seria interessante relacionar esse lugar indeterminado na linguagem de 


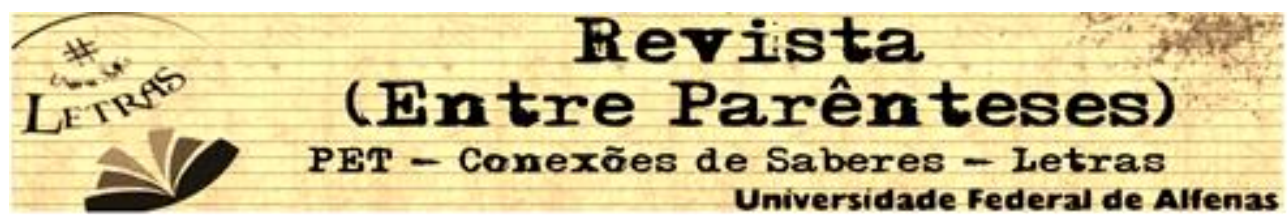

Bartleby, como estranhamento na própria ordem do sistema linguístico, ao efeito de uma agramaticalidade. Diga-se que a agramaticalidade, à qual se alude aqui, não diz respeito a um erro, na verdade, poderia ser entendida como se fosse uma fenda que se abre no interior da língua padrão e que, por essa abertura, chega o "vento de loucura" que se instala na linguagem. Daí, a sentença de Bartleby poder ser esse vento que sopra na linguagem e também ser uma indeterminação, fazendo com que a ordem e as regras, que regem o discurso, esvaiam-se.

A fórmula "desconecta" as palavras e as coisas, as palavras e as ações, mas também os atos e as palavras, ela corta a linguagem de qualquer referência (...). Por isso a fórmula apesar do aspecto correto funciona como uma autêntica agramaticalidade (idem, p. 97).

Essa autêntica agramaticalidade ajuda a indeterminar todo o caráter referencial que rege a linguagem cotidiana porque cinde qualquer referência. É como se a sentença abrisse um buraco negro no regaço da língua, desativando todos os atos de fala por meio dos quais poderia haver uma ordem ou um comando. Instala-se, portanto, uma espécie de gagueira na linguagem que tende ao desequilíbrio de sua homogeneidade, fazendo com que vibre cada partícula e cada termo (DELEUZE, 2011, p. 144). A expressão proferida por Bartleby torna-se uma resistência por meio de seu uso insólito, porque já não se refere somente ao uso incomum do verbo "preferir". Ela desequilibra todo o sistema referencial da linguagem em termos de uma agramaticalidade. A sentença torna-se indecifrável, ou ainda, indiscernível e, portanto, é assim que Bartleby resiste no plano da linguagem.

Como uma segunda justificativa à leitura de Deleuze, entende-se que a resistência de Bartleby não se atém somente ao plano da língua, ela se expande e chega ao "homem sem referências", fazendo com que o próprio homem, Bartleby, habite a "zona indiscernível". A fórmula "preferiria não", além de eliminar o sistema de referência da língua, abrindo uma fenda em seu interior, corrobora com a 


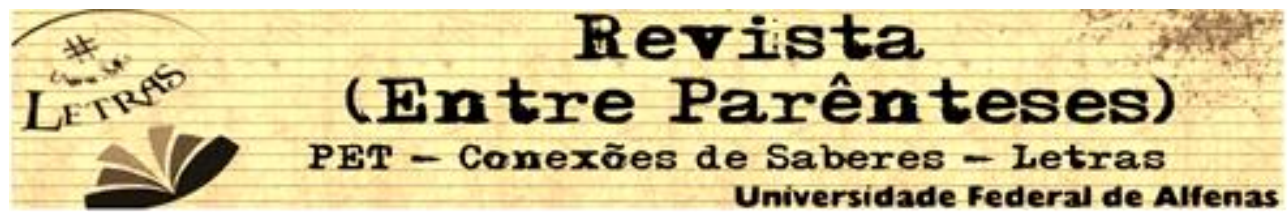

"vocação absoluta de Bartleby" porque causa uma separação entre as palavras e as coisas, entre as palavras e as ações e, também, entre os atos e as palavras.

[A fórmula] corta a linguagem de qualquer referência, em conformidade com a vocação absoluta de Bartleby, ser um homem sem referências, aquele que surge e desaparece, sem referência a si mesmo nem a outra coisa (DELEUZE, 2011, p. 97).

Bartleby é, portanto, "o homem sem posses, sem propriedades, sem qualidades, sem particularidades" (idem, p. 98) e ser assim, um homem sem referências, segundo Deleuze, não era algo incomum durante o século XIX. Foi justamente nesse período em que houve certa busca por um homem que não tivesse um nome, que se impusesse como resistência contra a industrialização das cidades e contra a mecanização do próprio homem. Diante desse quadro, um novo sujeito deveria surgir, um indivíduo que pudesse, de certa forma, ser a esperança de um novo mundo. É, portanto, nesse contexto que deveria nascer o homem sem referência.

Todo o século XIX será atravessado por essa busca do homem sem nome, regicida e parricida, Ulisses dos tempos modernos: o homem esmagado e mecanizado das grandes metrópoles, mas de onde se espera, talvez, que saia o homem do futuro ou de um mundo novo (idem, p. 98).

O escrivão foi contratado, como lembra Deleuze, sem nenhuma referência. O semblante calmo de Bartleby parecia dar ao advogado a impressão de ser um homem constante e regular. No entanto, mesmo com a percepção de que o novo contratado pudesse ser um empregado calmo e ordenado, o advogado submeteu-o a uma vigília, ou seja, o novo escrivão ficava, de certa forma, sob o controle do patrão, ao seu alcance, na mesma sala. Assim sendo, Bartleby realizou todo o trabalho mecanicamente até o momento em que advogado chama-o para conferir as cópias. Nesse instante decisivo, o escrivão liberou, pela primeira vez, a sua fórmula, 


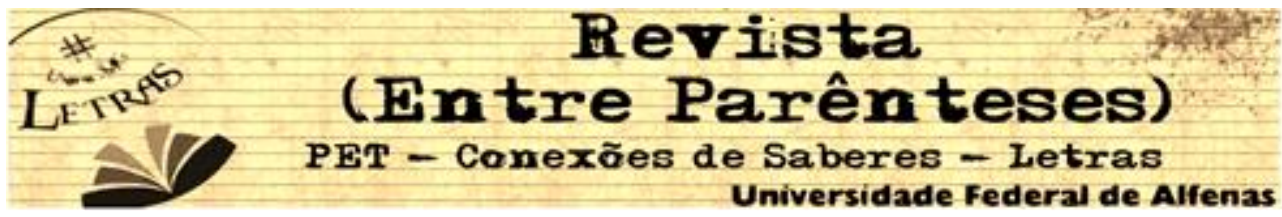

resistindo-se a conferir os documentos copiados.

Eis que Bartleby extrai dos escombros um 'traço de expressão', prefiro não, que vai proliferar sobre si, contaminar os outros, afugentar 0 advogado, mas também fazer fugir a linguagem, aumentar uma zona de indeterminação ou de indiscernibilidade tal que as palavras já não se distinguem umas das outras (idem, p. 100101).

É dessa forma que o homem, Bartleby, emperra a engrenagem do escritório, visto que o seu traço de expressão já não causa estranhamento somente no plano da linguagem, ele prolifera a tal ponto que acaba por contaminar a todos. Sendo assim, todo o sistema é desarticulado com a não atitude do novo escrivão. Depois de seu primeiro "preferiria não", muda-se toda a rotina do escritório. O escrivão já não é mais aquele que apenas cumpre seu dever e as ordens do chefe, e nem mesmo as recusa, ele apenas "preferiria não". Esse comportamento liberado pela fórmula é tão insólito e raro que faz com que alguns colegas de Bartleby reajam, não sem certa raiva, a ponto de desejarem restituí-lo ao trabalho por meio da força. $\mathrm{O}$ patrão tenta de todas as maneiras compreender, ou ainda, racionalizar sobre o empregado, porém sem obter sucesso. Bartleby não só "preferiria não" copiar, como "preferiria não" deixar o ambiente onde estava. "Preferindo não", o homem, Bartleby, não apanharia e nem bateria nos colegas; "preferindo não", Bartleby não compreende e nem se deixa compreender pelo patrão. Ele é fulminante em sua desarticulação, todo o sistema vigente no escritório rui diante dele e, assim, Bartleby resiste.

Seria, nesse sentido, que Bartleby habitaria um lugar indeterminado para além de qualquer referência. Nenhuma atitude externa consegue alcançá-lo, o próprio advogado tenta, em vão, entendê-lo. O sujeito aqui é sem referência absoluta, pois, como se envolto numa camada amorfa, não se liga a nenhum referencial que aponte para fora de si mesmo ou para si mesmo. Não há um desejo 


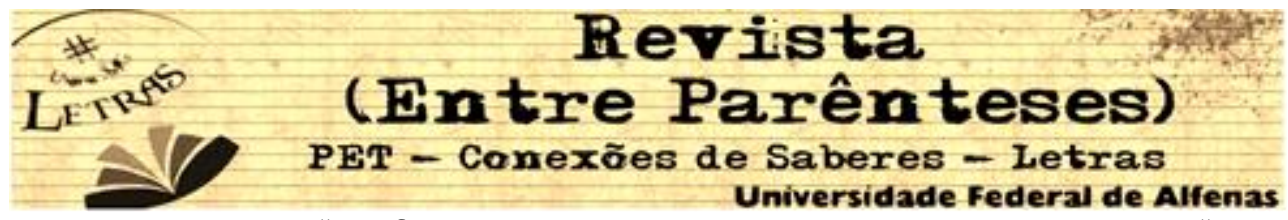

ou vontade, apenas um "preferiria não" que não nega nem a negação, "negativismo para além de toda negação".

Bartleby não pretende ser a significação de algo além do que ele parece ser, seja como metáfora ou símbolo. A leitura de Deleuze é muito cuidadosa quanto a delimitar um significado acabado para Bartleby, justamente porque ele parece ser aquele personagem que, como lembra Edgar Allan Poe, em "O homem da multidão", "es lässt sich nicht lesen". Bartleby escapa, resiste à interpretação, à leitura e à codificação, ao passo que emperra as estruturas linguísticas e sociais com o seu "preferiria não".

A fórmula restitui a Bartleby um enigma que, a todo o momento, foge à síntese da significação, e não se deixa ler. Contraposto ao escrivão, o advogado, em consonância com a sua profissão, é claro, objetivo e respeitador do sistema linguístico e social. Ambos os personagens se justificam com a distinção entre aqueles que se assemelham aos particulares e aos originais. Nesse sentido, os primeiros seriam aqueles modelados pelo próprio meio em que habitam, seguem as leis gerais de convivência e, consequentemente, não são resistência a nada, sobretudo, à ordem estabelecida das coisas.

Os particulares têm características que determinam sua forma, propriedades que compõem sua imagem; recebem influência de seu meio, e uns dos outros, de sorte suas ações e reações obedecem a leis gerais. Conservando cada vez um valor particular. Do mesmo modo, as frases que pronunciam Ihes são próprias, mas não deixam de obedecer às leis gerais da língua (DELEUZE, 2011, p. 108).

Distantes dessas características estão os originais, pois cada um deles possui a potência para derrubar qualquer forma que se faça explicável. Sopram a linguagem que apresenta um pensar indomável, sem racionalidade e, portanto, contumaz. Não querem ser universais e tampouco são particulares. Eles, a todo o instante, resistem ao conhecimento instrumental. 


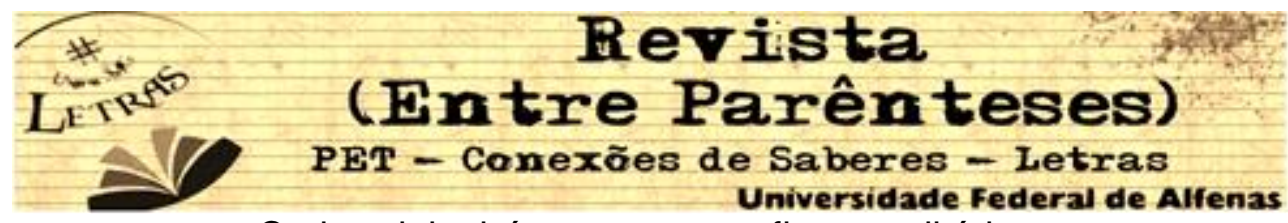

Cada original é uma potente figura solitária que extravasa qualquer forma explicável: lança flamejantes dardos-traços de expressão, que indicam a teimosia de um pensamento sem imagem, de uma questão sem resposta, de uma lógica extrema e sem racionalidade. Não têm nada de geral e não são particulares: escapam ao conhecimento, desafiam a psicologia. Mesmo as palavras que pronunciam transbordam das leis gerais da língua, assim como as simples particularidades da fala, levam toda a linguagem ao limite do silêncio e da música (idem, p. 109).

Cabe ainda realçar que "os originais", apesar de solitários, estão ligados ao mundo dos "particulares", não se separam porque é justamente no mundo mecanizado, objetivo e racional dos particulares que exercem a sua tarefa, ou seja, "revelam seu vazio, a imperfeição das leis, a mediocridade das criaturas particulares, o mundo como mascarada" (DELEUZE, 2011, p. 109). Mesmo estando ligados ao mundo dos particulares, os originais não sofrem influência do meio, ao contrário, desarticulam o próprio meio, perturbam a ordem estável das coisas, deixando desconexas as relações sociais e, também, as linguísticas. Portanto, não há dúvidas de que Bartleby seja um original porque não possui nada de particular e nem de universal.

Por fim, o delineamento do caminho aqui percorrido procurou entrever uma reflexão que justificasse a leitura de Gilles Deleuze sobre Bartleby. Desse modo, foram apresentadas duas justificativas que, sob a ótica deleuziana, versaram acerca da resistência do escrivão a alguns referenciais. Assim, a linguagem de Bartleby assumiu, num primeiro plano, a sua resistência, visto que a fórmula ao ser pronunciada não se refere a nada, nem a um querer fazer e nem a um não querer fazer, ou seja, ao copiar ou ao não copiar. Ela resiste à interpretação, travando toda a engrenagem do referencial linguístico. Esse estranhamento, identificado na linguagem de Bartleby, desdobrou-se até uma agramaticalidade que não deve ser entendida como erro, mas, sim, como um procedimento que visa a introduzir, no interior da língua, uma desarticulação das constantes linguísticas. 


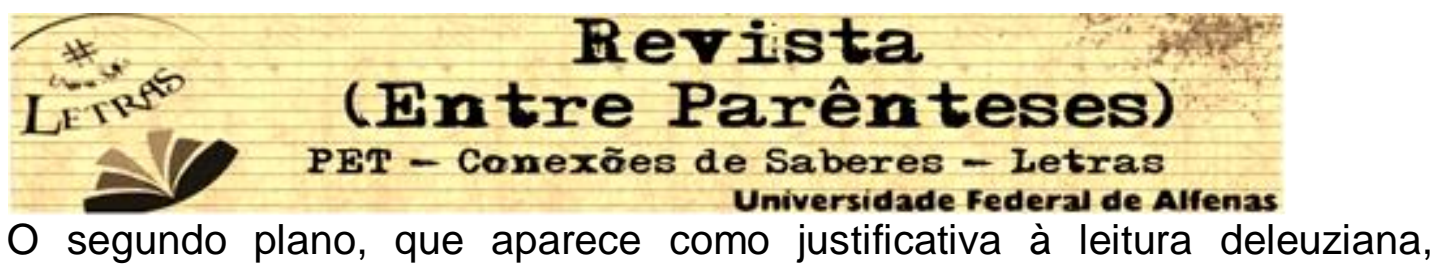
entende Bartleby como um homem sem referências, isto porque não há nele nenhuma posse, propriedade, qualidade ou particularidade. Diante disso, chegou-se à ideia de que o escrivão é uma personagem "original", ou seja, uma figura solitária que extravasa qualquer forma explicável. Ambas as justificativas aqui encontradas deságuam naquilo que Deleuze chamou de "zona indiscernível", ou seja, um lugar em que impera a resistência absoluta a qualquer tentativa explicativa racional. Portanto, é no indiscernível que Bartleby resguarda-se, deixando viger uma espécie de enigma absoluto.

\section{Referências bibliográficas:}

AGAMBEN, Giorgio. A fórmula, ou da potência. Em: Bartleby, ou da contingência. Trad. Vinícius Honesko. Belo Horizonte: Autêntica Editora, 2015, p. 26-35.

DELEUZE, Gilles. Bartleby, ou a fórmula. Em: Crítica e clínica. 2ª Ed. Trad. Peter Pál Pelbart. São Paulo: Editora 34, 2011, p. 91-117. . Gaguejou. Em: Crítica e clínica. $2^{a}$ Ed. Trad. Peter Pál Pelbart. São Paulo: Editora 34, 2011, p. 138-146.

MELVILLE, Herman. Bartleby, o escrivão. Trad. Gil de Carvalho. Lisboa: Assírio \& Alvim 2007.

Recebido em: 01/11/2016

Aceito em: 26/11/2016 